\title{
Activation of Pseudomonas aeruginosa elastase in Pseudomonas putida by triggering dissociation of the propeptide-enzyme complex
}

\author{
Peter Braun, $\uparrow$ Wilbert Bitter and Jan Tommassen
}

Department of Molecular Microbiology and Institute of Biomembranes, Utrecht University, Padualaan 8, $3584 \mathrm{CH}$ Utrecht, The Netherlands
Author for correspondence: Jan Tommassen. Tel: +31 30 2532999. Fax: +31302513655. e-mail: j.p.m.tommassen@bio.uu.nl

The propeptide of Pseudomonas aeruginosa elastase functions both as an intramolecular chaperone required for the folding of the enzyme and as an inhibitor that prevents activity of the enzyme before its secretion into the extracellular medium. Since expression of the lasB gene, which encodes elastase, in Pseudomonas putida did not result in extracellular elastase activity, it has been suggested that the enzyme is not recognized by the Xcp secretion machinery of the heterologous host. Here, it is demonstrated that the proenzyme is normally processed in $P$. putida and that it is indeed not actively secreted by the $X c p$ machinery. Nevertheless, substantial amounts of the enzyme were detected in the extracellular medium. Coimmunoprecipitations revealed that the extracellular enzyme was associated with the propeptide, which explains the lack of enzymic activity. Since the propeptide-enzyme complex in $P$. putida apparently does not dissociate spontaneously, it is concluded that a host-specific factor is required to induce this event. Mutants were selected which showed extracellular elastase activity. Two mutations, located within the lasB gene, were further characterized. These mutations, resulting in the substitution of Ala and Thr at positions -15 and -153 , respectively, of the propeptide (where position +1 is defined as the first residue of the mature enzyme) destabilized the propeptide-enzyme complex. It is concluded that Ala-15 and Thr-153 are required for the inhibitor function, but not for the chaperone function of the propeptide.

Keywords: Pseudomonas aeruginosa, Pseudomonas putida, protein folding, protein-protein interaction, elastase maturation

\section{INTRODUCTION}

The opportunistic pathogen Pseudomonas aeruginosa is able to secrete many proteins into the extracellular medium. Most of them, i.e. elastase (LasB), lipase, alkaline phosphatase, exotoxin A, two phospholipases $\mathrm{C}$, a putative aminopeptidase, a chitin-binding protein $(\mathrm{CbpB})$ and the staphylolytic protease LasA, are secreted via the type II secretion pathway (Wretlind \& Pavlovskis, 1984; Filloux et al., 1998; Braun et al., 1998; Folders et al., 2000). In this two-step pathway, the signal-sequence-dependent translocation across the inner membrane is mediated by the Sec machinery. The

†Present address: Department of Pharmaceutical Biology, Groningen University, Antonius Deusinglaan 1, 9713 AV Groningen, The Netherlands. subsequent secretion of periplasmic intermediates across the outer membrane is mediated by a machinery composed of at least 12 proteins, which are encoded by the xcp genes (for a review, see Filloux et al., 1998). Similar secretion systems have been found in many different Gram-negative bacteria (for a review, see Pugsley, 1993).

Like many other extracellular bacterial proteases, the proteolytic enzyme elastase is produced as a preproprotein. The propeptide functions as an intramolecular chaperone (Braun \& Tommassen, 1998) which is essential for the folding of elastase in the periplasm (McIver et al., 1995; Braun et al., 1996). After autocatalytic processing of the $52 \mathrm{kDa}$ proelastase (McIver et al., 1991), the propeptide $(18 \cdot 1 \mathrm{kDa})$ remains noncovalently associated with the $33 \mathrm{kDa}$ mature elastase 
(Kessler \& Safrin, 1988) and inhibits premature proteolytic activity of the enzyme in the periplasm (Kessler \& Safrin, 1994). The entire propeptide-enzyme complex is translocated across the outer membrane (Braun et al., 1998; Kessler et al., 1998), and dissociation of the complex and elastase-mediated degradation of the propeptide take place extracellularly. The process of dissociation, however, is poorly understood.

Previously, it was demonstrated in our laboratory that the expression of $P$. aeruginosa elastase in Pseudomonas putida does not result in any detectable extracellular enzyme activity (de Groot et al., 1991). It was postulated that the heterologous enzyme was not recognized by the Xcp secretion apparatus, which was demonstrated to be present in P. putida (de Groot et al., 1999). Alternatively, any other step in the complex biogenesis pathway of elastase could be defective in the heterologous host. The present study was set up to identify the step(s) that is/are blocked in the biogenesis of elastase in P. putida, and should eventually lead to further insight into this complicated process. We demonstrate that, amongst other steps, the dissociation of the propeptide-elastase complex is defective in the heterologous host and we describe a new class of propeptide mutations, which affect the inhibitor function, but not the chaperone function of the propeptide.

\section{METHODS}

Bacterial strains and growth conditions. The bacterial strains used are listed in Table 1. Cells were grown in LB medium with agitation at $30^{\circ} \mathrm{C}$ for $P$. putida or at $37^{\circ} \mathrm{C}$ for $P$. aeruginosa and Escherichia coli. For agar plates, media were solidified with $1.5 \%$ agar. The antibiotic concentrations used for plasmid maintenance were 40 and $25 \mu \mathrm{g}$ kanamycin $\mathrm{ml}^{-1}$ for P. putida and E. coli, respectively, and $100 \mu \mathrm{g}$ piperacillin $\mathrm{ml}^{-1}$ for P. putida and $100 \mu \mathrm{g}$ ampicillin $\mathrm{ml}^{-1}$ for E. coli. For maintenance of pMMB67EH-derivatives in $P$. putida, the addition of IPTG $(500 \mu \mathrm{M})$ was necessary since the expression of the $l a c I^{\mathrm{q}}$-encoded repressor appears to be deleterious in $P$. putida in the absence of IPTG (unpublished observation).

Plasmids and DNA manipulations. The plasmids used are listed in Table 2. Plasmid isolations from E. coli, restriction endonuclease digestions, ligations and agarose gel electrophoresis were performed according to standard procedures (Sambrook et al., 1989). Plasmids were isolated from P. putida by using a one-step miniprep method (Chowdhury, 1991). The enzymes used were purchased from Pharmacia and Fermentas. DNA fragments were isolated and purified from agarose gel using the JetSorb Gel Extraction Kit 600 (Genomed).

To express lasB in P. putida, plasmid pULB22 was constructed by cloning the lasB gene from pML27 as an EcoRI-SphI fragment in the multiple cloning site of pUR6500. Plasmids pPB25 and pPB26 were constructed by cloning the las $B$ mutant alleles from pULB22-32 and pULB22-34, respectively, as EcoRI-HindIII fragments in the multiple cloning site of pMMB67EH. Plasmid pPB46 was constructed by replacing the BssHII-NotI fragment of pML27 with that of pULB22-34.

Nucleotide sequences were determined using the Taq Dye Terminator Cycle Sequencing kit or the Taq Dye Primer Cycle Sequencing kit and the ABI 373A Automated DNA Sequencer (all from Perkin Elmer) according to the manufacturer's instructions. As a template, double-stranded DNA isolated from E. coli strain $\mathrm{DH} 5 \alpha$ was used. The primers used were Pri14 (5'-AGGTTTCTACGCTTGACC-3') , Pri15 (5' -GGCAAGCAGGTCACCCGC-3'), Pri16 (5'-CCGCCGAAGAAATGCGCG-3') (all purchased from Pharmacia) and the M13 universal sequencing primer (Perkin Elmer).

Transformation, mobilization and plasmid curing. Transformation of E. coli strains and transfer of plasmid DNA to $P$. putida by triparental mating, using the conjugative properties of pRK2013, were done as described previously (Braun et al., 1996). For the propagation of newly constructed plasmids or plasmids isolated from P. putida strains, E. coli strains PC2495 and 1046, respectively, were used. $P$. putida transconjugants were selected on LB agar plates supplemented with $25 \mu \mathrm{g}$ naladixic acid $\mathrm{ml}^{-1}$. To cure P. putida of pMMB67EH-based

\section{Table 1. Strains used}

\begin{tabular}{|c|c|c|}
\hline Strain & Relevant characteristics* & Source \\
\hline \multicolumn{3}{|l|}{ E. coli } \\
\hline PC2495 & $\begin{array}{l}\text { hsdS recA56 thi } \Delta\left(\text { lac-proAB) supE } \mathrm{F}^{\prime}\left(\text { pro }^{+} B^{+}\right.\right. \\
\operatorname{lacl}^{\mathrm{T}} \mathrm{Z} \Delta \mathrm{M} 15 \text { traD36) }\end{array}$ & NCCB \\
\hline DH5 $\alpha$ & $\begin{array}{l}\mathrm{F}^{-}, \text {thi-1 hsdR17 gyrA96 recA1 endA1 supE44 relA1 } \\
\Delta(\text { lacZYA-arg) U169 ( } 8 \text { 80dlacZ } \Delta \mathrm{M} 15)\end{array}$ & NCCB \\
\hline 1046 & $\mathrm{~F}^{-}$, met lac gal hsdS supF supE recA56 & NCCB \\
\hline \multicolumn{3}{|l|}{ P. putida } \\
\hline WCS358 & Wild-type isolate, $\mathrm{Nx}^{\mathrm{R}}$ & $\begin{array}{l}\text { Geels \& Schippers } \\
\text { (1983) }\end{array}$ \\
\hline CE1427 & WCS358 xсpA:: $\mathrm{Km}^{\mathrm{R}}$ & de Groot et al. (1996) \\
\hline CE1430 & WCS358 xcpRST:: $\mathrm{Km}^{\mathrm{R}}$ & de Groot et al. (1996) \\
\hline \multicolumn{3}{|c|}{ P. aeruginosa } \\
\hline PA103-II & PAO1, elastase-negative & Guzzo et al. (1990) \\
\hline
\end{tabular}

${ }^{*} \mathrm{Km}^{\mathrm{R}}$, kanamycin resistance; $\mathrm{Nx}^{\mathrm{R}}$, naladixic acid resistance; NCCB, the Netherlands Culture Collection of Bacteria. 
Table 2. Plasmids used

\begin{tabular}{|c|c|c|c|}
\hline Plasmid & Size $(\mathrm{kb})$ & Relevant characteristics* & Reference \\
\hline pUC18 & $2 \cdot 7$ & $\mathrm{Amp}^{\mathrm{R}}$ ColE1, $\phi 80 \mathrm{~d} l a c Z$, lac promoter & Norrander et al. (1983) \\
\hline pUR6500 & $10 \cdot 1$ & pMMB67EH::Km ${ }^{\mathrm{R}} \mathrm{Amp}^{\mathrm{s}}$ & Frenken et al. (1993) \\
\hline pULB22 & $12 \cdot 6$ & $\mathrm{Km}^{\mathrm{R}}$, las $B$ in $\mathrm{pUR} 6500$ & This work \\
\hline pULB22-32 & $12 \cdot 6$ & $\mathrm{Km}^{\mathrm{R}}$, derivative of pULB22, encoding elastase with $\mathrm{A}-15 \mathrm{~V}$ substitution & This work \\
\hline pULB22-34 & $12 \cdot 6$ & $\mathrm{Km}^{\mathrm{R}}$, derivative of pULB22, encoding elastase with $\mathrm{T}-153 \mathrm{I}$ substitution & This work \\
\hline pMMB67EH & $8 \cdot 9$ & $\mathrm{Amp}^{\mathrm{R}}$ IncQ, tac promoter & Fürste et al. (1986) \\
\hline pML27 & $11 \cdot 5$ & $A m p^{\mathrm{R}}$, las $B$ in $\mathrm{pMMB67EH}$ & de Groot et al. (1991) \\
\hline pPB25 & $11 \cdot 4$ & $\begin{array}{l}\text { Amp }{ }^{\mathrm{R}} \text {, las } B \text { from pULB22-32, encoding elastase with } \mathrm{A}-15 \mathrm{~V} \text { substitution, } \\
\text { in } \mathrm{pMMB} 67 \mathrm{EH}\end{array}$ & This work \\
\hline pPB26 & $11 \cdot 4$ & $\begin{array}{l}\text { Amp }^{\mathrm{R}} \text {, lasB from pULB22-34, encoding elastase with } \mathrm{T}-153 \mathrm{I} \text { substitution, } \\
\text { in } \mathrm{pMMB67EH}\end{array}$ & This work \\
\hline pPB46 & $11 \cdot 5$ & $\begin{array}{l}\text { Amp }{ }^{\mathrm{R}} \text {, lasB containing the BssHII-NotI fragment of pULB22-34, encoding } \\
\text { elastase with } \mathrm{T}-153 \mathrm{I} \text { substitution, in pMMB67EH }\end{array}$ & This work \\
\hline pRK2013 & & $\mathrm{Km}^{\mathrm{R}} \mathrm{Tra}^{+} \mathrm{Mob}^{+}$ & $\begin{array}{l}\text { Figurski \& Helinski } \\
\text { (1979) }\end{array}$ \\
\hline
\end{tabular}

$* \mathrm{Km}^{\mathrm{R}}$, kanamycin resistance; $\mathrm{Amp}^{\mathrm{R}}$, ampicillin resistance; $\mathrm{Amp} \mathrm{s}^{\mathrm{S}}$, ampicillin sensitivity.

plasmids, cells were grown overnight in LB medium without antibiotics or IPTG, and plated on LB agar plates; piperacillinsensitive colonies were then selected after streaking on appropriate plates.

Chemical mutagenesis and selection of mutants. P. putida containing pULB22 was mutagenized by incubating $1 \mathrm{ml}$ cells from an overnight culture for $2 \mathrm{~h}$ at $30^{\circ} \mathrm{C}$ with an equal volume of a solution containing $4 \%$ EMS (Sigma) in $0.5 \times \mathrm{SV}$ medium (Lugtenberg et al., 1976). Cells were pelleted by centrifugation $(4000 \mathrm{~g}, 10 \mathrm{~min}$, room temperature), washed with $5 \% \mathrm{Na}_{2} \mathrm{~S}_{2} \mathrm{O}_{3}$ and resuspended in $1 \mathrm{ml} \mathrm{LB}$ medium. After a 40-fold dilution in this medium, cells were grown overnight. Mutants producing active elastase were selected on protease indicator plates, which consisted of tryptic soy broth (Becton and Dickinson) supplemented with $1.5 \%$ non-fat dried milk (Protifar; Nutricia), $0.5 \mathrm{mM}$ IPTG and $1.5 \%$ agar. For further characterizations, protease indicator plates that contained LB medium instead of tryptic soy broth were used.

Pulse-labelling, (co-)immunoprecipitations, SDS-PAGE and Western blotting. Pulse-labelling of $P$. putida, separation of cells and extracellular medium, and immunoprecipitations were performed as described for $P$. aeruginosa (Braun et al., 1996). The interaction between the propeptide and elastase in the extracellular medium was studied by co-immunoprecipitation. For this purpose, cells were removed from overnight cultures by centrifugation $(6700 \mathrm{~g}, 3 \mathrm{~min}$, room temperature) and the supernatant obtained was centrifuged again (13 $000 \mathrm{~g}, 3 \mathrm{~min}$, room temperature). To the cell-free, extracellular fluid, specific polyclonal antiserum was added and the immunocomplexes were precipitated with protein ASepharose CL-B4 (Pharmacia) as described previously (Braun et al., 1996). To examine the secretion of elastase and the propeptide, cells from overnight cultures were separated from the extracellular fluid by centrifugation $(6700 \mathrm{~g}, 3 \mathrm{~min}$, room temperature) and the supernatant further cleared by an additional centrifugation step $(13000 \mathrm{~g}, 3 \mathrm{~min}$, room temperature). From both fractions, proteins were precipitated with $5 \%$ TCA.

SDS-PAGE and Western blotting were performed as described previously (Braun et al., 1996), except that $12 \%$ acrylamide gels were used and peroxidase activity on blots was also visualized by enhanced chemiluminescence (ECL). Polyclonal antisera directed against elastase or against the propeptide were preabsorbed with cell extracts of $P$. aeruginosa strain AP103-II or E. coli strains PC2495(pUC18) and DH5 $\alpha$ (pUR6500), respectively.

Enzyme assay. $\beta$-Lactamase activity was determined using pyridine-2-azo- $p$-dimethylaniline cephalosporin (PADAC) (Cal Biochem) as a substrate (Howard \& Buckley, 1985).

\section{RESULTS}

\section{Elastase maturation in $P$. putida}

Previously, it was demonstrated that the introduction of the elastase-encoding las $B$ gene into $P$. putida strain WCS358 did not result in the formation of active enzyme (de Groot et al., 1991). Consistently, no halo was formed around colonies of this strain containing las $B$ plasmid pULB22 on protease indicator plates (Fig. 1a, colony 2). Only after prolonged incubation of the plates, local clearance in the vicinity of, but not surrounding the entire colony was occasionally observed (Fig. 1b, colony 2 ). These results indicate that at least one step in the biogenesis of elastase is disturbed in this host. Elastase production and maturation in P. putida was studied by analysing cells and culture supernatant of strain WCS358 carrying pML27 by SDS-PAGE and Western blotting. Mature elastase was detected mainly intracellularly (Fig. 2a, lane 1), and its apparent molecular mass was indistinguishable from that of mature elastase expressed in $P$. aeruginosa (data not shown). These results indicate that the translocation across the inner membrane, propeptide-mediated folding of the mature enzyme and the subsequent autoproteolytic processing of the proenzyme were not hampered. Furthermore, a substantial amount of mature elastase (approx. 15\%) was detected extracellularly (Fig. 2a, lane 3). Since similar amounts of elastase were detected in the super- 
Plasmid EMS-treated Wild-type LasB

A-15V LasB

T-153I LasB

Xcp

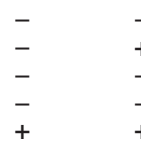

12

(a)

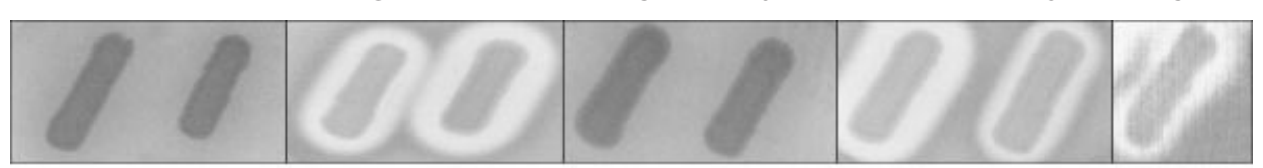

(b)

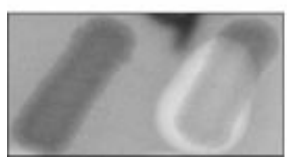

Fig. 1. Protease activity of plasmid-containing $P$. putida derivatives. Cells shown in (a) were grown on protease indicator plates for $3 \mathrm{~d}$ at $30^{\circ} \mathrm{C}$. In (b), the incubation was subsequently continued at room temperature for another $3 \mathrm{~d}$. Colonies: 1, WCS358(pMMB67EH); 2, WCS358(pULB22); 3, WCS358(pULB22-32); 4, WCS358(pULB22-34); 5, WCS358(pMMB67EH); 6, WCS358(pML27); 7, WCS358(pPB46); 8, xcpA mutant strain CE1427(pPB46); 9, xcpRST mutant CE1430(pPB26). The presence of wild-type or mutant alleles of the las $B$ gene on the plasmids, and of wild-type or deletion of $x c p$ genes on the chromosome is indicated above the figure. Haloes around the colonies indicate the presence of active extracellular elastase.

natant of the $x c p R S T$ mutant strain CE1430 of P. putida (data not shown), its presence in the extracellular fraction appears to result from outer membrane leakage or cell lysis, rather than from active secretion. Consistently, a similar portion (approx. 15\%) of the periplasmic marker enzyme $\beta$-lactamase, expressed from pML27, was detected extracellularly, as determined by measuring its enzymic activity (data not shown). In conclusion, the maturation of elastase seems to proceed normally in $P$. putida, but the enzyme is not actively secreted, even though substantial amounts of the protein appear extracellularly.

\section{Defective dissociation of the propeptide-enzyme complex in P. putida}

The presence of a substantial amount of elastase in the extracellular medium of $P$. putida (Fig. 2a, lane 3) is not consistent with the results of the plate assay (Fig. 1a, colony 2), which did not reveal the presence of extracellular protease activity. Apparently, the elastase detected extracellularly is in an inactive form. This result could be explained by assuming that the extracellular elastase remained non-covalently associated with its propeptide, which is known to be an inhibitor of the enzyme (Kessler \& Safrin, 1994). To test this possibility, the supernatant was analysed for the presence of the propeptide. In the extracellular medium of $P$. aeruginosa, the propeptide could not normally be detected, since it was extracellularly degraded by elastase (Braun et al., 1998; Kessler et al., 1998). In contrast, the propeptide was detected in the cell-free culture supernatant of $P$. putida (Fig. 2 b, lane 3 ). To examine whether the propeptide was still associated with elastase in the supernatant, co-immunoprecipitation experiments were performed using antibodies directed against elastase. The propeptide present in the spent medium (Fig. 3a, lane 1) could indeed be coimmunoprecipitated with mature elastase (Fig. 3b, lane 1). Hence, the extracellular elastase detected in P. putida remains stably associated with the propeptide and is thereby inhibited in its proteolytic activity. Apparently, the dissociation of the propeptide-enzyme complex is not a spontaneous extracellular process, but requires a host-specific factor.

\section{Destabilization of the propeptide-enzyme complex by propeptide mutations}

The observation that the propeptide remains associated with elastase when the proenzyme is expressed in $P$. putida allows for the identification of residues that are important for its inhibitor functions. To this end, mutants of $P$. putida expressing active extracellular elastase were isolated after EMS treatment of strain WCS358 containing pULB22 and screening for colonies forming haloes on protease indicator plates. From approximately 6000 colonies screened, 40 colonies were identified that produced an active protease. To determine whether the mutations were located on the plasmid or on the chromosome, plasmid DNA was isolated from the mutants and reintroduced into $P$. putida WCS358. In only 2 out of the 40 cases, the resulting transconjugants showed the formation of a halo on protease indicator plates (Fig. 1a, colonies 3 and 4), demonstrating that the mutations were located on the plasmids. In the other 38 cases, the mutation is apparently located on the chromosome. The analysis of these mutants, which will be done in a separate study, may lead to the identification of the host-specific factor that induces the dissociation of the propeptide-enzyme complex. Exchanging of restriction fragments revealed 
(a)

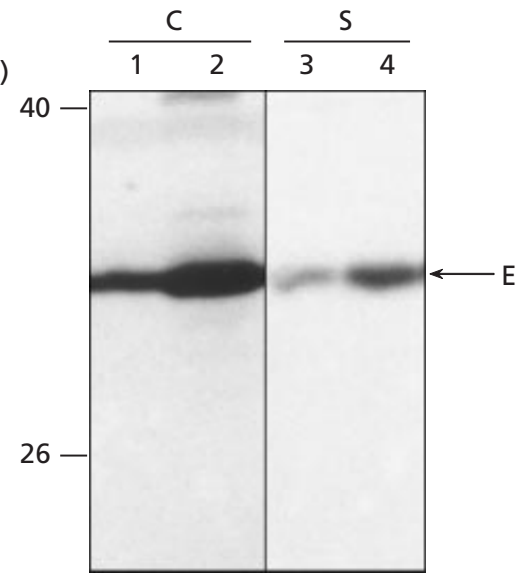

(b)

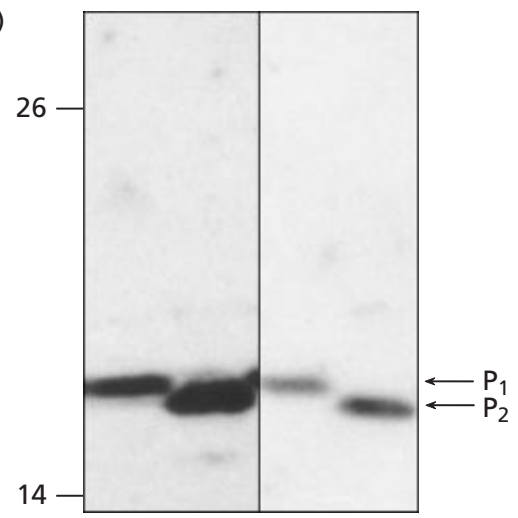

Fig. 2. Maturation of $P$. aeruginosa elastase, expressed in $P$. putida. Cells were grown at $30{ }^{\circ} \mathrm{C}$ and elastase expression was induced during overnight growth. Samples corresponding to $50 \mu \mathrm{l}$ cells (C) or $360 \mu \mathrm{l}$ supernatant (S) were analysed using SDS-PAGE and Western blotting. Mature elastase and the propeptide were detected using polyclonal antisera directed against elastase (a) or against the propeptide (b). Lanes: 1 and 3, WCS358(pML27) (wild-type LasB); 2 and 4, WCS358(pPB26) ( $T-153$ I mutant LasB). The positions of elastase (E), wild-type propeptide $\left(\mathrm{P}_{1}\right)$ and $T-153 \mathrm{I}$ mutant propeptide $\left(\mathrm{P}_{2}\right)$ are indicated on the right and molecular mass markers (in $\mathrm{kDa}$ ) on the left.

that the plasmid-encoded mutations are present on the NotI-SalI and the BssHII-NotI fragments (Fig. 4) of pULB22-32 (data not shown) and pULB22-34 (Fig. 1a, colony 7), respectively. The nucleotide sequences of these fragments were determined. Both fragments contained a single point mutation, resulting in the substitution of Ala at position -15 by Val and of Thr at position -153 by Ile in the case of pULB22-32 and of pULB22-34, respectively (where +1 is defined as the $\mathrm{N}$ terminal amino acid residue of the mature elastase; Fig. 4). Both substitutions are located within the propeptide of elastase.

One possible explanation for the extracellular proteolytic activity detected was that the mutations in the propeptide resulted in an improved recognition by the $\mathrm{Xcp}$ secretion machinery of $P$. putida. However, analysis

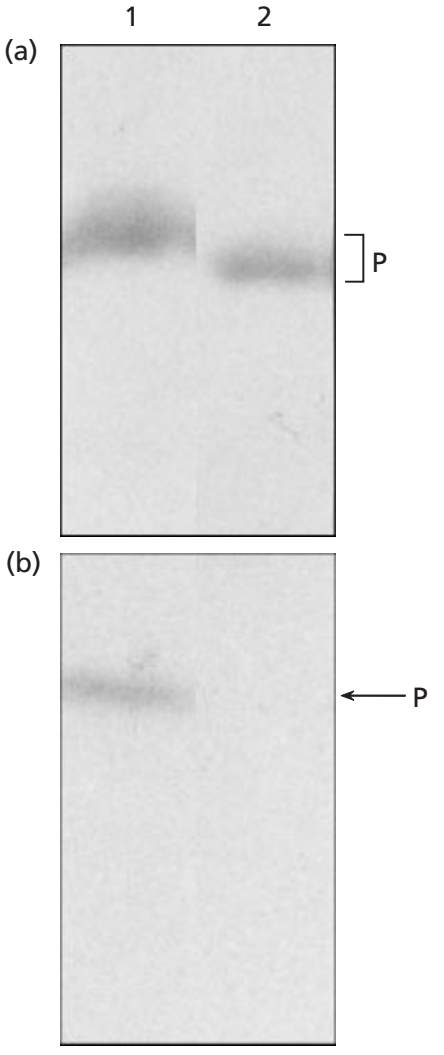

Fig. 3. Dissociation of the propeptide-enzyme complex. Cells of $P$. putida strains were grown overnight at $30^{\circ} \mathrm{C}$ with agitation. From the supernatant, proteins were precipitated with TCA (a) or immunoprecipitated using an anti-elastase antiserum (b). Samples corresponding to $360 \mu \mathrm{l}$ (a) or $1 \mathrm{ml}$ (b) supernatant were analysed using SDS-PAGE and Western blotting. Blots were probed with a polyclonal antiserum directed against the propeptide. Lanes: 1, WCS358(pML27) (wild-type LasB); 2, WCS358(pPB26) ( $T-1531$ mutant LasB). The position of the propeptide $(P)$ is indicated.

of cells and supernatant fractions revealed that only approximately $15 \%$ of the total amount of elastase produced was extracellular (Fig. 2a, compare lanes 2 and 4; only shown for the $\mathrm{T}-153 \mathrm{I}$ mutation), as was also observed for the wild-type elastase. Also, the formation of haloes around the colonies of the $x c p A$ mutant strain CE1427 (Fig. 1a, colony 8) and the $x c p R S T$ mutant strain CE1430 (Fig. 1a, colony 9) indicated that elastase was released by the cells in an Xcp-independent manner. Finally, pulse-chase experiments revealed that the kinetics of the release of elastase into the extracellular medium were not changed by the $\mathrm{T}-153 \mathrm{I}$ substitution (Fig. 5, compare a and b), and that the mutant enzyme was released with similar kinetics in the wild-type strain and in the $x c p R S T$ mutant strain (Fig. 5, compare $b$ and $c$ ). An alternative explanation for the mutant phenotype was that the substitutions in the propeptide destabilize the interaction with the enzyme, resulting in extracellular enzyme activity. Like the mature elastase (Fig. 2a, lanes 2 and 4), the T-153I mutant propeptide was usually detected both inside the 


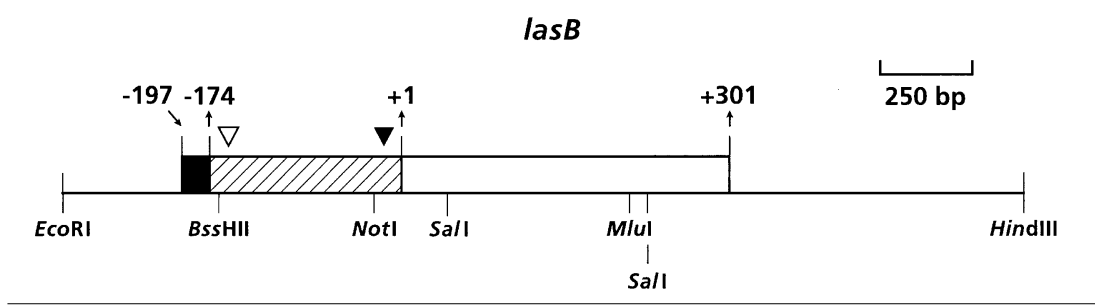

Fig. 4. Localization of mutations in lasB. Various regions of the wild-type las $B$ gene, indicated by the restriction sites, were replaced by the corresponding parts of the mutant plasmids pULB22-32 and pULB22-34. The recombinant plasmids were introduced into strain WCS358 and elastase secretion was evaluated. Plasmid pULB22-32 contains an $\mathrm{A}-15 \mathrm{~V}$ substitution $(\boldsymbol{\nabla})$; plasmid pULB22-34 contains a $T-153$ l substitution $(\nabla)$. Numbers indicate amino acid positions, where the first residue of mature elastase is defined as +1 . DNA segments encoding the signal sequence (black box), the propeptide (hatched box) and the mature elastase (white box) are indicated.

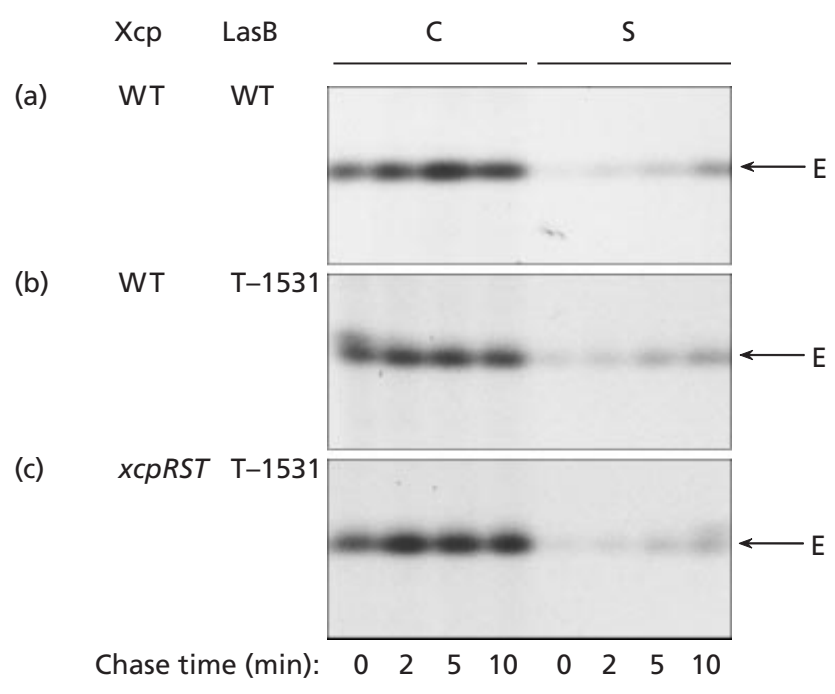

Fig. 5. Kinetics of elastase release into the extracellular medium. Cells of the indicated P. putida strains were grown to an $\mathrm{OD}_{600}$ of 0.35 at $30{ }^{\circ} \mathrm{C}$. Thirty minutes after the induction of elastase expression, the cells were labelled for $3 \mathrm{~min}$, followed by a chase for the indicated periods. Cells (C) were separated from the supernatant $(S)$, and proteins present in both fractions were precipitated with TCA and dissolved in Triton buffer; elastase was then immunoprecipitated. Samples corresponding to $234 \mu \mathrm{l}$ cells and $195 \mu \mathrm{l}$ supernatant were applied to SDS-PAGE and analysed by autoradiography. (a) WCS358(pML27), (b) WCS358(pPB26), (c) CE1430(pPB26). The presence of wildtype (WT) or mutant alleles of the las $B$ gene on the plasmids, and of WT or deletions of $x c p$ genes on the chromosome is indicated on the left. The position of mature elastase (E) is indicated on the right.

cells (Fig. 2b, lane 2) and in the supernatant (Fig. 2b, lane 4). However, co-immunoprecipitations with antiserum directed against mature elastase revealed that it was no longer associated with the mature enzyme (Fig. 3b, lane 2). The apparent molecular mass of the propeptide was somewhat reduced as compared with that of the wildtype propeptide (Fig. 2b, compare e.g. lanes 3 and 4). It is not immediately clear whether this is a direct result of the amino acid substitution or of partial degradation by the active enzyme (Braun et al., 1998). In some experi- ments, the mutant propeptide could not be detected in the supernatant, probably because it was degraded entirely by the mature elastase. Identical results were obtained with cells expressing the A-15V mutant elastase, but the apparent molecular mass of this mutant propeptide was indistinguishable from that of the wildtype (data not shown). Hence, we conclude that in the mutants a portion of mature elastase is extracellular, just as in the wild-type case. However, due to the mutations in the propeptide, the propeptide-enzyme complexes are destabilized, resulting in dissociation of the complexes and activation of the enzyme.

\section{DISCUSSION}

Previously, it was reported that expression of $P$. aeruginosa elastase in $P$. putida and $P$. fluorescens does not result in extracellular elastase activity (de Groot et al., 1991). We anticipated that (at least) one step in the biogenesis of elastase was affected. Therefore, the maturation of this enzyme was examined, and it appeared that mature elastase was produced. This result implies that the elastase precursor is normally translocated across the inner membrane and that periplasmic propeptide-mediated folding of the enzyme occurs, resulting in the autoproteolytic processing of the proenzyme. The majority of the elastase produced by $P$. putida remained intracellular, probably because of poor or no recognition by the Xcp secretion system of the heterologous host. Nevertheless, a significant amount of elastase was released extracellularly, most likely as a result of partial lysis of the cells. However, this extracellular elastase was inactive because it remained associated with the propeptide, which is known to function as an inhibitor of the enzyme (Kessler \& Safrin, 1994). Apparently, the extracellular dissociation of the propeptide-enzyme complex is not an intrinsic property of the complex, and an additional factor, which is lacking in $P$. putida, is required for this process. What could be the nature of this additional factor? Recently, Michel et al. (2000) reported that alterations in the $P$. aeruginosa lipopolysaccharide structure can result in leakage of inactive elastase into the medium even in the absence of a functional Xcp machinery. It seems likely 
that in this case also the propeptide remained associated with the enzyme, thereby keeping it inactive. Apparently, secretion of the propeptide-enzyme complex via a functional Xcp secretion machinery is essential for activation of the enzyme. Probably, the interaction of the complex with a component of the Xcp machinery alters the conformation of the complex, which facilitates its dissociation. In the absence of such a contact, the dissociation of the complex is dynamically disfavoured, but may occasionally occur spontaneously. The resulting active elastase molecules could degrade propeptides in neighbouring complexes, thereby increasing locally the proteolytic activity. This would explain the local clearance in the vicinity of $P$. putida cells expressing wild-type elastase after prolonged incubation on protease indicator plates (Fig. 1b). Support for the possible role of the Xcp machinery in the dissociation of the propeptide-elastase complex may be obtained if the mutations on the chromosome that were obtained in the present study and resulted in the dissociation of the propeptide-elastase complex were found to be located in the $x c p$ gene cluster of $P$. putida. These mutations are currently being characterized. Alternatively, the introduction of a gene bank of $P$. aeruginosa in $P$. putida expressing las $B$ may help to identify the factors required for the dissociation of the propeptide-enzyme complex. Interestingly, an additional factor also seems to be required for the release of the propeptide from the alpha toxin of Clostridium septicum. After the proteolytic processing of the protoxin in vitro, the propeptide did not dissociate immediately from the toxin, but only upon interaction with the target membranes (Sellman \& Tweten, 1997).

Many extracellular bacterial proteases are, like elastase, produced as proenzymes. The propeptides usually have a dual function, i.e. they function as an intramolecular chaperone required for the folding of the mature domain and as an inhibitor which prevents premature activity of the enzyme. Mutations that affect the former function of the propeptide have been described, for example in the case of subtilisin (Kobayashi \& Inouye, 1992). However, mutations affecting the inhibitor function, without affecting the chaperone function, have, to our knowledge, not been described so far. The stability of the propeptide-enzyme complex in $P$. putida enabled us to identify intragenic information that is important for the inhibitor function but not for the chaperone function of the propeptide. Two mutations in the las $B$ structural gene were isolated which resulted in the presence of extracellular elastase activity in $P$. putida. Both mutations resulted in an amino acid substitution in the propeptide. The presence of active extracellular elastase is explained in these cases by the fact that the mutant propeptides were no longer associated with elastase in the extracellular medium. The mutations probably destabilize the propeptide-enzyme complex, thereby relieving the inhibitor function of the propeptide, without affecting its role as a folding catalyst. The $C$. septicum alpha toxin and the related aerolysin from Aeromonas hydrophila are also produced as prepro- proteins. Interestingly, mutations in their propeptides, resulting in destabilization of the propeptide-toxin complexes, have been described (Sellman \& Tweten, 1997; van der Goot et al., 1994). In all these cases, the amino acid residues that are substituted in the mutants are likely to be located at the contact site of the propeptides with the mature proteins.

Interestingly, expression of the $\mathrm{A}-15 \mathrm{~V}$ mutant LasB in $P$. aeruginosa resulted in a severe growth retardation, leakage of the cells and, finally, in cell lysis (unpublished observation). These data stress the importance of the role of the propeptide as an inhibitor of the enzyme. Relieving this function by triggering the premature dissociation of the propeptide in the periplasm is apparently harmful for the cells. It also implies the need for a well-regulated mechanism for the dissociation of the propeptide-enzyme complex. From these data, one can speculate that the dissociation and the secretion of the propeptide-enzyme complex are linked. However, it is not immediately clear within this concept why the expression of the mutant protein in P. putida, which fails to secrete the enzyme, had no detrimental effects. Furthermore, expression of the T-153I mutant LasB did not have such harmful effects in $P$. aeruginosa, possibly because this substitution was less effective in relieving the inhibitor function of the propeptide than the $\mathrm{A}-15 \mathrm{~V}$ substitution.

In conclusion, the autoproteolytic processing of proelastase per se is not the trigger for the dissociation of the propeptide-enzyme complex. After the propeptidemediated folding of elastase and the processing event, the propeptide remains non-covalently, but stably associated with the enzyme. This stable interaction can be weakened by amino acid substitutions in the propeptide, without affecting the function of the propeptide as a folding catalyst. Additional factors, which are probably supplied by the Xcp secretion machinery, could be required for the dissociation. Hence, it appears that the dissociation of the propeptide-elastase complex is a well-coordinated process and reflects an important step in the biogenesis of elastase.

\section{ACKNOWLEDGEMENTS}

We thank E. Kessler for providing anti-propeptide antiserum, A. Lazdunski for providing anti-elastase antiserum and $P$. aeruginosa strain PA103-II, the Netherlands Culture Collection of Bacteria (NCCB) for providing E. coli strains, T. Hoeimakers of the Hubrecht Laboratory for sequence analysis and A. de Groot for the construction of pULB22. The continuous interest and helpful suggestions of $\mathrm{M}$. Koster were very much appreciated. This work was supported by the Netherlands Foundation for Chemical Research, with financial aid from the Netherlands Organization for the Advancement of Research and from the European Community EU grant bio4-CT960119.

\section{REFERENCES}

Braun, P. \& Tommassen, J. (1998). Function of bacterial propeptides. Trends Microbiol 6, 6-8. 
Braun, P., Tommassen, J. \& Filloux, A. (1996). Role of the propeptide in folding and secretion of elastase of Pseudomonas aeruginosa. Mol Microbiol 19, 297-306.

Braun, P., de Groot, A., Bitter, W. \& Tommassen, J. (1998). Secretion of elastinolytic enzymes with their propeptides by Pseudomonas aeruginosa. J Bacteriol 180, 3467-3469.

Chowdhury, K. (1991). One step 'miniprep' method for isolation of plasmid DNA. Nucleic Acids Res 19, 2792.

Figurski, D. H. \& Helinski, D. R. (1979). Replication of an origincontaining derivative of plasmid RK2 dependent on a plasmid function provided in trans. Proc Natl Acad SciU $S$ A 76, 1648-1652.

Filloux, A., Michel, G. \& Bally, M. (1998). GSP-dependent protein secretion in Gram-negative bacteria: the Xcp system of Pseudomonas aeruginosa. FEMS Microbiol Rev 22, 177-198.

Folders, J., Tommassen, J., van Loon, L. C. \& Bitter, W. (2000). Identification of a chitin-binding protein secreted by Pseudomonas aeruginosa. J Bacteriol 182, 1257-1263.

Frenken, L. G. J., Bos, J. W., Visser, C., Müller, W., Tommassen, J. \& Verrips, C. T. (1993). An accessory gene, $\operatorname{lip} B$, required for the production of active Pseudomonas glumae lipase. Mol Microbiol 9, 579-589.

Fürste, J. P., Pansegrau, W., Frank, R., Blöcker, H., Scholz, P., Bagdasarian, M. \& Lanka, E. (1986). Molecular cloning of the plasmid RP4 primase region in a multi-host-range tacP expression vector. Gene 48, 119-131.

Geels, F. P. \& Schippers, B. (1983). Reduction of yield depressions in high frequency potato cropping soil after seed tuber treatment with antagonistic fluorescent Pseudomonas spp. Phytopathol Z 108, 207-214.

van der Goot, F. G., Hardie, K. R., Parker, M. W. \& Buckley, J. T. (1994). The C-terminal peptide produced upon proteolytic activation of the cytolytic toxin aerolysin is not involved in channel formation. J Biol Chem 269, 30496-30501.

de Groot, A., Filloux, A. \& Tommassen, J. (1991). Conservation of $x c p$ genes, involved in the two-step protein secretion process, in different Pseudomonas species and other gram-negative bacteria. Mol Gen Genet 229, 278-284.

de Groot, A., Krijger, J.-J., Filloux, A. \& Tommassen, J. (1996). Characterization of type II protein secretion ( $x c p$ ) genes in the plant growth-stimulating Pseudomonas putida, strain WCS358. Mol Gen Genet 250, 491-504.

de Groot, A., Gerritse, G., Tommassen, J., Lazdunski, A. \& Filloux, A. (1999). Molecular organization of the $x c p$ gene cluster in Pseudomonas putida: absence of an $x c p X$ (gspK) homologue. Gene 226, 35-40.

Guzzo, J., Murgier, M., Filloux, A. \& Lazdunski, A. (1990). Cloning of the Pseudomonas aeruginosa alkaline protease gene and secretion of the protease into the medium by Escherichia coli. $J$ Bacteriol 172, 942-948.
Howard, S. P. \& Buckley, J. T. (1985). Protein export by a gramnegative bacterium: production of aerolysin by Aeromonas bydrophila. J Bacteriol 161, 1118-1124.

Kessler, E. \& Safrin, M. (1988). Synthesis, processing, and transport of Pseudomonas aeruginosa elastase. J Bacteriol 170, 5241-5247.

Kessler, E. \& Safrin, M. (1994). The propeptide of Pseudomonas aeruginosa elastase acts as an elastase inhibitor. J Biol Chem 269, 22726-22731.

Kessler, E., Safrin, M., Gustin, J. K \& Ohman, D. E. (1998). Elastase and the LasA protease of Pseudomonas aeruginosa are secreted with their propeptides. J Biol Chem 273, 30225-30231.

Kobayashi, T. \& Inouye, M. (1992). Functional analysis of the intramolecular chaperone. Mutational hot spots in the subtilisin pro-peptide and a second-site suppressor mutation within the subtilisin molecule. J Mol Biol 226, 931-933.

Lugtenberg, B., Peters, R., Bernheimer, H. \& Berendsen, W. (1976). Influence of cultural conditions and mutations on the composition of the outer membrane proteins of Escherichia coli. Mol Gen Genet 147, 251-262.

Mclver, K., Kessler, E. \& Ohman, D. E. (1991). Substitution of active-site His-223 in Pseudomonas aeruginosa elastase and expression of mutated lasB alleles in Escherichia coli show evidence for autoproteolytic processing of proelastase. J Bacteriol 173, 7781-7789.

Mclver, K. S., Kessler, E., Olson, J. C. \& Ohman, D. E. (1995). The elastase propeptide functions as an intramolecular chaperone required for elastase activity and secretion in Pseudomonas aeruginosa. Mol Microbiol 18, 877-889.

Michel, G., Ball, G., Goldberg, J. B. \& Lazdunski, A. (2000). Alteration of the lipopolysaccharide structure affects the functioning of the Xcp secretory system in Pseudomonas aeruginosa. J Bacteriol 182, 696-703.

Norrander, J., Kempe, T. \& Messing, J. (1983). Construction of improved M13 vectors using oligodeoxynucleotide-directed mutagenesis. Gene 26, 101-106.

Pugsley, A. P. (1993). The complete general secretory pathway in Gram-negative bacteria. Microbiol Rev 57, 50-108.

Sambrook, J., Fritsch, E. F. \& Maniatis, T. (1989). Molecular Cloning: a Laboratory Manual, 2nd edn. Cold Spring Harbor, NY : Cold Spring Harbor Laboratory.

Sellman, B. R. \& Tweten, R. K. (1997). The propeptide of Clostridium septicum alpha toxin functions as an intramolecular chaperone and is a potent inhibitor of alpha toxin-dependent cytolysis. Mol Microbiol 25, 429-440.

Wretlind, B. \& Pavlovskis, O. R. (1984). Genetic mapping and characterization of Pseudomonas aeruginosa mutants defective in the formation of extracellular proteins. J Bacteriol 158, 801-808.

Received 2 May 2000; revised 17 July 2000; accepted 24 July 2000. 